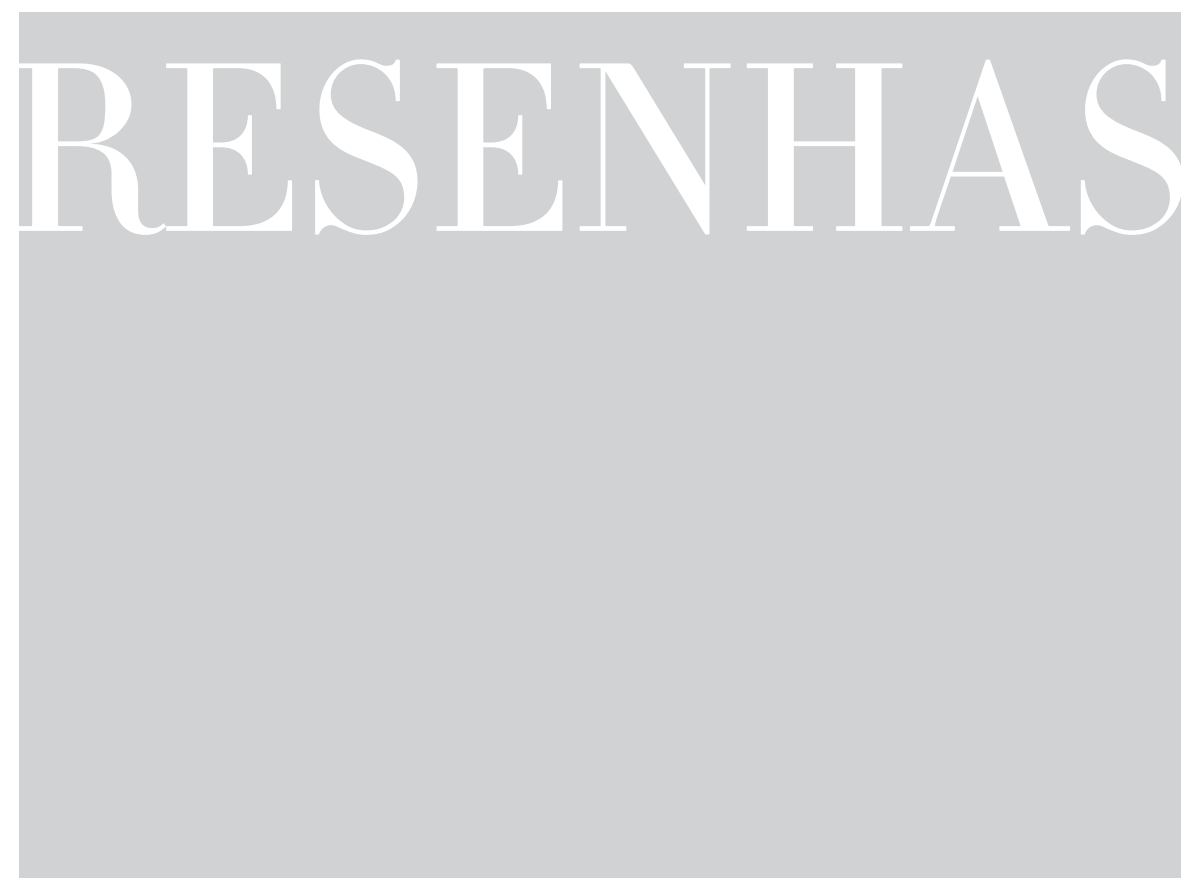

\title{
QUALIDADE NA EDUCAÇ̃̃O INFANTIL E AVALIAÇÃO DE CONTEXTO: EXPERIÊNCIAS ITALIANAS DE PARTICIPAÇÃO
}

http://dx.doi.org/10.1590/198053143136

BONDIOLI, Ana; SAVIO, Donatella (Org.). Participação e qualidade

em educação da infância: percursos de compartilhamento reflexivo

em contextos educativos. Curitiba: Editora UFPR, 2013.

A educação para as crianças pequenas no cenário contemporâneo brasileiro tem enfrentado inúmeros desafios, decorrentes das mudanças legislativas, políticas, sociais e pedagógicas que vêm ocorrendo nos últimos 15 a 20 anos.

Dentre os vários desafios vivenciados está a melhoria da qualidade da oferta em educação infantil nas creches e pré-escolas em território nacional. A melhoria dessa qualidade requer articulação no disposto nas Diretrizes Curriculares Nacionais para essa etapa da educação básica. Tal enfrentamento requer condições básicas de infraestrutura, formação apropriada de professores e um percurso de avaliação.

Nesse contexto, nos deparamos com a publicação Participação e qualidade em educação da infância: percursos de compartilhamento reflexivo em contextos educativos, livro organizado pelas professoras Anna Bondioli e Donatella Savio, que constitui-se como privilégio e possibilidade de enriquecimento das nossas concepções e práticas. A obra é composta de diferentes artigos que abordam questões relativas a experiência de acompanhamento e avaliação desenvolvida junto a diversas instituições 
de educação infantil - creches e pré-escolas, da cidade de Módena, na Itália. O conteúdo discutido decorre de aproximadamente 10 anos de trabalho de assessoramento e pesquisa formativa realizado na parceria entre a Università Degli Studi di Pavia e órgão municipal de educação, no referido município.

Essa obra inicia com a explicitação dos pressupostos e princípios relativos à concepção de qualidade e avaliação compartilhada entre todos os envolvidos. Nesse sentido, a avaliação é compreendida como uma prática que permite à instituição refletir sobre si, sobre sua identidade, verificar e consolidar consensos acerca de seu projeto educativo; o processo avaliativo deve ser articulado à formação, a fim de potencializar as melhorias necessárias; os instrumentos a serem utilizados na avaliação devem contar com a validação consensual dos envolvidos, independentemente de se tratar de instrumentos já existentes ou de instrumentos a serem construídos ad hoc. Em síntese, para o grupo de autores envolvidos no processo de avaliação formativa discutido nesse livro, avaliar convoca aqueles que, por razões diversas, se sensibilizam e se comprometem com a saúde e o "bem-estar" de uma instituição de educação infantil.

A distinção dessa obra está no fato de trazer a público o extenso e bem estruturado percurso de discussão e análise da qualidade dos serviços de creches e pré-escolas, concretizado em uma experiência de pesquisa-formação, a partir do uso de diferentes instrumentos avaliativos, escolhidos ou elaborados para tal.

Outra marca distintiva dessa obra está na apresentação das reflexões sobre as escolhas metodológicas quanto ao trabalho de análise e monitoramento da qualidade realizado. Nela se discutem: a participação como promoção interna; os novos modos de ser pais e o envolvimento das famílias junto às instituições; o desafio de promover a participação e a brincadeira das crianças; a promoção da qualidade pela avaliação; a avaliação como experiência compartilhada e a autoavaliação; o empenho dos educadores; os efeitos sobre as instituições.

A obra traduzida pelo professor Ernani Fritoli e com a revisão técnica das professoras Catarina Moro e Gizele de Souza, mantém no texto em língua portuguesa expressões e posições que se afinam com o contexto de produção dos textos originais, tendo conservado a sua estrutura original dos textos, bem como o estilo narrativo de seus autores.

Tomando tais questões como base, podemos adentrar nos conteúdos dos sete capítulos que compõem a publicação e o modo como estão organizados no livro.

O livro está estruturado em duas partes. Na primeira, intitulada "O Método", os temas principais são a qualidade e a participação, que, para as autoras, são dois elementos indissociáveis. A segunda parte, “As Experiências”, está organizada em três seções: na seção I, aborda-se 
o percurso de compartilhamento da filosofia educativa da instituição entre professoras e pais nas pré-escolas do município; na Seção II, as experiências de pesquisa e avaliação sobre a participação das famílias; e, na Seção III, temos o tema da participação da criança utilizando a brincadeira como forma de expressão.

O primeiro capítulo, de Anna Bondioli (uma das organizadoras), intitulado "Construir compartilhando a qualidade: a contribuição das partes interessadas”, expõe e discute o tema da participação, articulando-o ao da qualidade e da avaliação e propõe um modelo de "avaliação compartilhada”, específico para os contextos educativos de creches e pré-escolas. No Capítulo 2, chamado “O valor da participação”, Adriana Querzè, assessora do município de Módena, também se enfrenta a questão da participação nas instituições, enfocando-o em relação ao papel e aos compromissos políticos e culturais das administrações locais, evidenciando os pressupostos da experiência da cidade de Módena.

Na segunda parte do livro, a primeira seção é composta por dois capítulos. No Capítulo 3, "Avaliar a realização do projeto educativo: uma experiência compartilhada entre pais e professoras das pré-escolas", Anna Bondioli faz uma reflexão sobre o seu percurso de formadora e idealizadora do projeto, compartilhando suas experiências referentes ao processo de recrutamento, coleta de dados, leituras interpretativas e devolutivas. O Capítulo 4, "Os efeitos sobre a instituição”, de Lucia Selmi (coordenadora pedagógica de Módena), apresenta um olhar interno, uma reflexão do processo pelas coordenadoras pedagógicas, professores e a participação das famílias.

A segunda seção, da Parte II, os capítulos 5 e 6 refletem sobre o percurso de autoavaliação das formas de participação por professores e pais nas creches de Módena. A participação, nas suas diversas modalidades, é o elemento norteador do trabalho de consultoria da pesquisadora Anna Bondioli, discutida no Capítulo 5, "A participação como objeto e estratégia de pesquisa”. No Capítulo 6, "A participação das famílias: reflexões, escolhas e projetos”, Francesca D’Alfonso e Patrizia Rilei apresentam os percursos e os resultados do ponto de vista da coordenação.

O Capítulo 7, "A Brincadeira e a participação da criança: um desafio educativo e seus pontos nodais”, que compõe a terceira seção da Parte II, traz um elemento muito importante em todo o processo educativo: a criança. Donatella Savio reflete sobre o direito e a capacidade de a criança participar ativamente da vida da instituição. Para tanto, reflete sobre a importância da brincadeira como lugar privilegiado para observar o ponto de vista infantil. A pesquisadora apresenta a experiência das educadoras das creches de Módena que, com base na reflexão sobre o protagonismo e participação infantil, realizaram um instrumento de avaliação da "boa creche lúdica”. 
A reflexão realizada nos diferentes capítulos que constituem o livro é feita por intermédio do relato e da discussão quanto ao processo de avaliação dos serviços de creche e pré-escola, com vistas à expansão da qualidade e à garantia da participação de todos os agentes envolvidos no processo de criar e educar as crianças pequenas - gestores, professores e pais.

Certamente, esse livro é uma obra que fornece aos leitores brasileiros elementos importantes sobre o tema (tão atual e significativo) da avaliação na educação infantil. Os conceitos de participação e qualidade são importantes no processo de avaliação proposto, principalmente contribuições para a gestão pública relacionadas à infância.

\section{GIOCONDA GHIGGI}

Mestranda do Programa de Pós-Graduação em Educação e integrante do Núcleo de Estudos e Pesquisas em Infância e Educação Infantil - NEPIE - da Universidade Federal do Paraná - UFPR -, Curitiba, Paraná, Brasil; professora e pedagoga da Prefeitura Municipal de Curitiba, Curitiba, Paraná, Brasil

gighiggi@yahoo.com.br 